\title{
Characterization of the Rapid-Onset Type of Behavioral Sensitization to Amphetamine in Mice: Role of Drug-Environment Conditioning
}

\author{
Cibele Cristina Chinen*,', Rulian Ricardo Faria' and Roberto Frussa-Filho' \\ 'Departamento de Farrmacologia, Escola Paulista de Medicina, Universidade Federal de São Paulo, São Paulo, SP, Brazil
}

\begin{abstract}
A rapid-onset type of behavioral sensitization (ROBS) has been demonstrated in rats treated with a single 'priming' injection of amphetamine (AMP). In that species, however, this phenomenon was restricted to AMP-induced stereotyped behavior (SB), not occurring for the locomotor-stimulant effect (LSE) of AMP and not reflecting environment-specific sensitization. In the present study, the ROBS was characterized in the mouse. Mice received a single 'priming' intraperitoneal injection of $5.0 \mathrm{mg} / \mathrm{kg}$ AMP which was paired or not with environment. At different intervals (3, 4 or $5 \mathrm{~h}$ ) subgroups were tested for AMP ( 1.5 or $5.0 \mathrm{mg} / \mathrm{kg}$ )-induced SB or AMP $(1.5 \mathrm{mg} / \mathrm{kg})$-induced open-field LSE. Results showed that: $(\mathrm{I})$ in the absence of drug-environment association, a priming injection of AMP increased the SB induced by a $1.5 \mathrm{mg} / \mathrm{kg}$ AMP challenge injection given $3 \mathrm{~h}$ (but not 4 or $5 \mathrm{~h}$ ) later; (2) when the dose of AMP challenge injection was increased to $5.0 \mathrm{mg} / \mathrm{kg}$, an enhancement of SB was verified at all the intervals tested (3, 4, and $5 \mathrm{~h}$ ); (3) when animals were tested in an open field, the priming injection of AMP produced an increase in the LSE of a $1.5 \mathrm{mg} / \mathrm{kg}$ AMP challenge injection, given $4 \mathrm{~h}$ later; (4) drug-environment association increased both SB and locomotion after a saline challenge injection and potentiated the rapid-onset sensitization of both behaviors in AMP-challenged mice. Collectively, these results demonstrate that the ROBS phenomenon also occurs in mice, is extended to AMP-induced LSE, and is markedly potentiated by (but does not depend on) environmental conditioning.

Neuropsychopharmacology (2006) 3 I, I5I-159. doi:I0.1038/sj.npp. I 300789; published online 8 June 2005
\end{abstract}

Keywords: amphetamine; conditioning; stereotypy; locomotion; behavioral sensitization

\section{INTRODUCTION}

While there is tolerance to many of the effects of repeated drug treatments, the psychomotor and positive reinforcing effects of amphetamine (AMP) and other drugs of abuse often become progressively greater with repeated administration (Robinson and Becker, 1986; Piazza et al, 1990; De Vries et al, 1998). This phenomenon, called behavioral sensitization, is usually measured in terms of locomotion or stereotypy in rodents (Robinson and Becker, 1986; Wise et al, 1996; Camarini et al, 2000). Sensitization of AMPinduced stereotyped behavior (SB) is considered to be an important model of dopaminergic nigrostriatal plasticity (Robinson and Becker, 1986). As regards sensitization of the locomotor-stimulatory effect of AMP (and other drugs of abuse), this model has been suggested to be useful for

\footnotetext{
*Correspondence: Dr CC Chinen, Escola Paulista de Medicina, UNIFESP-Edifício Leal Prado I andar, Rua Botucatu, 862-CEP 04023062-São Paulo, SP, Brazil, Tel: + 55 || 5549 4I22, Fax: 55 || 5542 4176, E-mail: cibchinen@uol.com.br or chinen.farm@epm.br Received 24 November 2004; revised 20 April 2005; accepted 21 April 2005

Online publication: 3 May 2005 at http://www.acnp.org/citations/ Npp050305040549/default.pdf
}

studying mechanisms underlying both dopaminergic mesoaccumbens plasticity (Henry and White, 1991; Wolf et al, 1994) and drug craving in humans (Robinson and Berridge, 1993).

The extent to which behavioral sensitization is induced by drug pre-exposure is highly dependent on the environmental context in which the injections are given as well as on the nature of the pretreatment regimen. Concerning the environmental context, it has been suggested that environmental cues might be conditioned stimuli for drug-like conditioned responses, potentiating the development of behavioral sensitization (Hayashi et al, 1980; Pierce and Kalivas, 1997; Costa et al, 2001; Frussa-Filho et al, 2004). Although sensitization of the locomotor-activating effect of AMP and other drugs of abuse has been also observed when drug injections are not paired with the observation environment (Bellot et al, 1996, 1997; Costa et al, 2001), this environmental modulation of sensitization is especially interesting because it is well known that environmental cues trigger craving and drug-seeking behavior in humans (Childress et al, 1986; Niaura et al, 1988; Carter and Tiffany, 1999).

With respect to the nature of the pretreatment regimen, it has been demonstrated that it is not necessary to repeatedly administer AMP for long periods of time to produce 
behavioral sensitization. Indeed, a single injection of AMP has been reported to enhance both stereotypy (Browne and Segal, 1977; Ellison and Morris, 1981) and locomotor stimulation (Vanderschuren et al, 1999a) produced by a subsequent injection of AMP given weeks later. Within this context, a more important variable appears to be the interval between AMP treatment (or AMP single injection) and the challenge injection of the drug. Indeed, several studies have found that the magnitude of AMP-induced behavioral sensitization gradually increases with prolonged withdrawal after AMP-repeated treatment (Kolta et al, 1985; Paulson et al, 1991; Vanderschuren et al, 1999b) or after AMP single exposure (Vanderschuren et al, 1999a).

The above-mentioned temporal profile of the behavioral sensitization phenomenon was however questioned by studies performed by Kuczenski and Segal (1999a, b). They demonstrated that the behavioral response of rats to low, nonstereotypy doses of AMP $(0.5-1.5 \mathrm{mg} / \mathrm{kg})$ at very short intervals $(3-5 \mathrm{~h})$ after an acute, 'priming', injection with $4.0 \mathrm{mg} / \mathrm{kg}$ AMP resulted in the emergence of intense, focused stereotypies in the absence of an altered caudate-putamen extracellular dopamine response. Such a finding might be especially important within the context of binge patterns of stimulant abuse involving frequent administration of the drug at short intervals. However, its clinical implications appear to be considerable attenuated by the experimental suggestion that this rapid-onset behavioral sensitization phenomenon did not occur for the locomotor-stimulant effect (LSE) of AMP and did not reflect environment-specific sensitization (Kuczenski and Segal, 1999a).

The present study had three purposes. These were to determine (1) if this rapid-onset sensitization of AMPinduced SB would also be verified in mice, (2) whether or not the phenomenon would be also demonstrated for the LSE of the drug, and (3) whether or not it would be dependent on (or at least be influenced by) environmental conditioning.

\section{MATERIALS AND METHODS}

\section{General Methods}

Subjects. Male EPM-M1 mice weighing $30-40 \mathrm{~g}$ were used. The animals arrived at the experimental laboratory at least 10 days before the beginning of the experiments. They were housed in plastic cages $(32 \times 42 \times 18 \mathrm{~cm}), 15$ per cage, with ad libitum access to food and water. Light/dark cycle (lights on at $07: 00 \mathrm{~h}$, off at $19: 00 \mathrm{~h})$ and temperature $\left(22^{\circ} \mathrm{C}\right)$ were kept constant. All experiments took place between 08:00 and 18:00 h. The animals were maintained and used in accordance with the guidelines of the Committee on Care and Use of Laboratory Animal Resources, National Research Council, USA.

Test agents. AMP (Sigma) was used. The drug was freshly diluted in saline (SAL) solution and was given intraperitoneally in volumes not greater than $10 \mathrm{ml} / \mathrm{kg}$ body weight. SAL was used as control solution.

Stereotypy studies. The animals were observed for SB in wire mesh cages $(16 \times 30 \times 18 \mathrm{~cm})$ free of water and food. Stereotypy was quantified every $5 \mathrm{~min}$ for $150 \mathrm{~min}$ after
AMP administration according to the scoring system proposed by Setler et al (1976), with some modifications validated in our laboratory for mice. Briefly, scores varying from 0 to 4 were attributed to an animal's behavior by an observer who was unaware of the drug treatment. The grading system was as follows: 0 , asleep or stationary; 1 , active; 2 , active with predominantly stereotyped sniffing and rearing; 3, stereotyped sniffing with bursts of licking and/or gnawing and biting; 4, continual licking and/or gnawing of cage grids. Animals were used only once.

Open-field studies. At $15 \mathrm{~min}$ after injection, the animals were individually placed in the center of the open-field arena for direct quantification of locomotion frequency during $5 \mathrm{~min}$. The open-field apparatus used in the present study was a circular wooden box $(40 \mathrm{~cm}$ in diameter and $50 \mathrm{~cm}$ high) with an open top and a floor divided into 19 squares. Hand-operated counters were used to score locomotion frequency (number of floor units entered) during the 5-min sessions. This period of time has been demonstrated to be effective in detecting AMP-induced behavioral sensitization in mice (Bellot et al, 1997; Costa et al, 2001; Frussa-Filho et al, 2004). All the observations were conducted blind. The animals were used only once.

\section{Experimental Procedure}

Experiment 1. Time-response curve to $5.0 \mathrm{mg} / \mathrm{kg}$ AMP acute administration in mice. In all, 20 mice were habituated in individual polypropylene cages $(20 \times 30 \times 12.5 \mathrm{~cm})$ (IC) for $150 \mathrm{~min}$. After this time, 10 animals received an intraperitoneal injection of SAL $(\mathrm{NaCl} 0.9 \%)$ and the other 10 mice received an intraperitoneal injection of $5.0 \mathrm{mg} / \mathrm{kg}$ AMP. Immediately later, they were placed in stereotypy observation cages for SB quantification.

Experiment 2. Validation of the phenomenon of rapidonset sensitization of AMP-induced $S B$ in mice and possible involvement of drug-environment association. In total, 117 mice were allocated to two groups (57-60 animals each). Animals of the first group were habituated for 150 min in stereotypy observation cages (OC) and mice of the second group were habituated in IC. After this period, animals received an intraperitoneal injection of $\mathrm{NaCl} 0.9 \%$ (SAL) or $5.0 \mathrm{mg} / \mathrm{kg}$ AMP (a dose which is effective in inducing intense and focused SB in this species, in our laboratorial conditions). Immediately after the respective injections, animals that had been habituated in IC were placed in OC (PAIR) and animals that had been habituated in OC were placed in IC (NPAIR). The animals were maintained in the respective environments for $150 \mathrm{~min}$. After this period, all animals were placed in their home cages. Animals of the four resulting groups (SALNPAIR, AMP-NPAIR, SAL-PAIR, AMP-PAIR) were subdivided into three groups and received a challenge injection of $1.5 \mathrm{mg} / \mathrm{kg}$ AMP (an ineffective dose to promote intense and focused SB in mice, in our laboratorial conditions) 3, 4 or $5 \mathrm{~h}$ after their respective 'priming' injections). Immediately afterwards, all animals were placed in stereotypy observation cages and SB was quantified. All the animals were observed simultaneously, varying the time of the priming injection. 
Experiment 3. Rapid-onset sensitization of AMP-induced $S B$ in mice and possible involvement of drug-environment association: effect of a higher dose of AMP challenge injection. In all, 120 mice were allocated to two groups (60 animals each). Half of the animals were habituated for $150 \mathrm{~min}$ in stereotypy observation cages (OC) and the other half were habituated in IC as described in experiment 2. Animals of the four resulting groups (SAL-NPAIR, AMPNPAIR, SAL-PAIR, AMP-PAIR) were subdivided into three groups and received a challenge injection of $5.0 \mathrm{mg} / \mathrm{kg}$ AMP 3,4 , or $5 \mathrm{~h}$ after their respective priming injections. Immediately later, all animals were placed in stereotypy observation cages and SB was quantified. All the animals were observed simultaneously, varying the time of the priming injection.

Experiment 4. Rapid-onset sensitization of AMP-induced $S B$ in mice and possible involvement of drug-environment association: effect of a SAL challenge injection.

(a) A total of 39 mice were allocated to two groups of 19-20 animals each. Animals were habituated and received injections as described in experiment 2. At $3 \mathrm{~h}$ after their respective priming injections, animals of each group (SAL-NPAIR, AMP-NPAIR, SAL-PAIR, and AMP-PAIR) received a SAL challenge injection and were, immediately later, placed in the stereotypy observation cages, for quantification of this behavior.

(b) A total of 40 mice were allocated to two groups of 20 animals each. Animals were habituated and received injections as described in experiment 2. At $4 \mathrm{~h}$ after their respective priming injections, animals of each group (SAL-NPAIR, AMP-NPAIR, SAL-PAIR, and AMP-PAIR) received a SAL challenge injection and were, immediately later, placed in the stereotypy observation cages, for quantification of this behavior.

Experiment 5. Demonstration of the LSE of $5.0 \mathrm{mg} / \mathrm{kg}$ in the open-field behavior of mice. In all, 14 mice received SAL injection $(n=6)$ or $5.0 \mathrm{mg} / \mathrm{kg}$ AMP $(n=8)$. After $15 \mathrm{~min}$, locomotor activity in the open field (OF) was quantified.
Experiment 6. Demonstration of the phenomenon of rapid-onset sensitization of AMP-induced locomotor activation in mice and the involvement of drug-environment association. A total of 40 mice were allocated to two groups (20 animals each). Half of the animals were habituated for $150 \mathrm{~min}$ in an $\mathrm{OF}$ and the other half were habituated in IC. After this period, they received an intraperitoneal injection of $\mathrm{NaCl} 0.9 \%$ (SAL) or $5.0 \mathrm{mg} / \mathrm{kg}$ AMP. Immediately after the respective priming injections, animals that had been habituated in the IC were placed in the OF (PAIR) and animals that had been habituated in the OF were placed in the IC (NPAIR). The animals were maintained in the respective environments for $150 \mathrm{~min}$. After this period, all animals were placed in their home cages. At $4 \mathrm{~h}$ after their respective priming injections, animals of the four resulting groups (SALNPAIR, AMP-NPAIR, SAL-PAIR, and AMP-PAIR) received a challenge injection of $1.5 \mathrm{mg} / \mathrm{kg}$ AMP. After $15 \mathrm{~min}$, all the animals were placed in the $\mathrm{OF}$ and locomotor activity was measured.

Experiment 7. Rapid-onset sensitization of AMP-induced locomotor stimulation in mice and possible involvement of drug-environment association: effect of a SAL challenge injection. In all, 39 mice were allocated to two groups of 19-20 animals each. Animals were habituated and received injections as described in experiment 6 . At $4 \mathrm{~h}$ after their respective priming injections, animals of each group (SAL-NPAIR, AMP-NPAIR, SAL-PAIR, and AMPPAIR) received a SAL challenge injection and, $15 \mathrm{~min}$ later, were placed in an OF for locomotor activity quantification.

\section{RESULTS}

Experiment 1. Time-Response Curve to $5.0 \mathrm{mg} / \mathrm{kg}$ AMP Acute Administration in Mice

Figure 1 shows the time-response curve to the $\mathrm{SB}$ of mice acutely treated with $5.0 \mathrm{mg} / \mathrm{kg}$ AMP. As compared to SAL-treated mice, the scores of SB presented by AMP-treated mice were significantly higher (Student's $t$-test) until $135 \mathrm{~min}$ after injection. Thus, by $150 \mathrm{~min}$ after

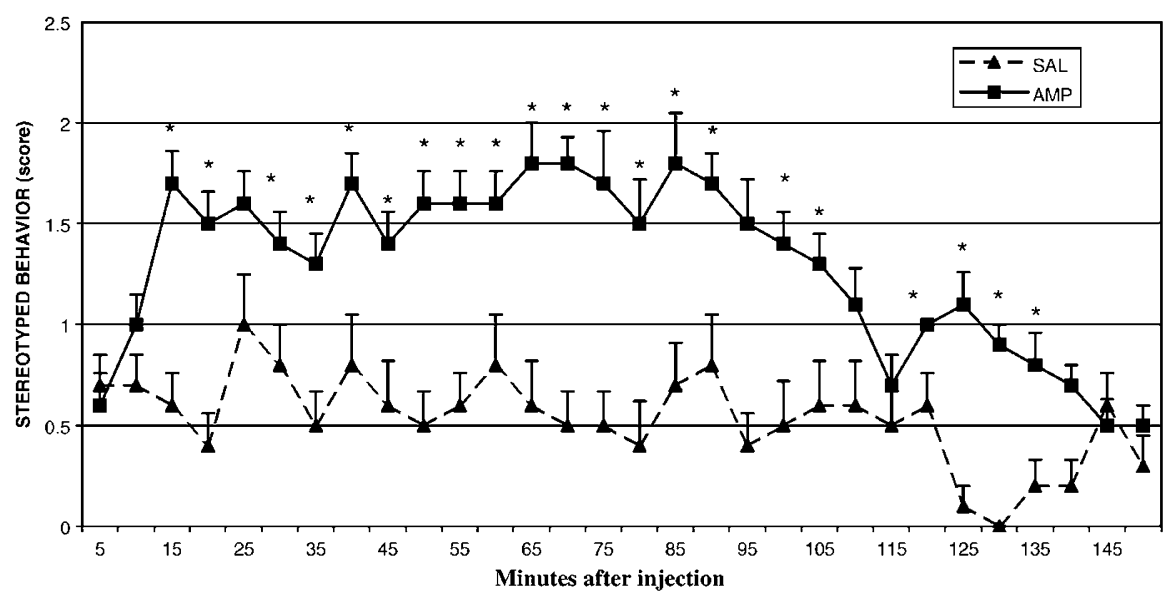

Figure I Experiment I. Time-response curve to $5.0 \mathrm{mg} / \mathrm{kg}$ AMP acute administration in mice. In all, 20 mice were habituated in IC for I50 min. After this time, 10 animals received an intraperitoneal injection of SAL $(\mathrm{NaCl} 0.9 \%)$ and the other 10 mice received an intraperitoneal injection of $5.0 \mathrm{mg} / \mathrm{kg} \mathrm{AMP}$. Immediately later, they were placed in stereotypy observation cages for SB quantification. ${ }^{*} p<0.05$ compared to the control group (SAL). Student's $t$-test. 
$5.0 \mathrm{mg} / \mathrm{kg}$ AMP treatment, SB had completely ceased. Table 1 shows the total values of the SB during the 150-min observation. The Student's $t$-test revealed a significant difference between SAL and AMP $(T(18)=7.80$; $p<0.001)$

Experiment 2. Validation of the Phenomenon of RapidOnset Sensitization of AMP-Induced SB in Mice and Possible Involvement of Drug-Environment Association. Figure 2 shows the SB induced by $1.5 \mathrm{mg} / \mathrm{kg}$ AMP in animals pretreated with a priming injection of SAL or $5.0 \mathrm{mg} / \mathrm{kg}$ AMP (associated or not with the observation cage), given 3, 4 , or $5 \mathrm{~h}$ before. A three-way ANOVA revealed significant effects for pretreatment (SAL or AMP) $(\mathrm{F}(1,105)=50.71$; $p<0.001)$, pairment (NPAIR or PAIR) $(\mathrm{F}(1,105)=24.72$; $p<0.001)$, and time $(3,4$, or $5 \mathrm{~h}$ after injection) $(\mathrm{F}(2,105)=4.72 ; p<0.001)$, and also for interaction between pretreatment and pairment $(\mathrm{F}(1,105)=16.15 ; p<0.001)$ and between pretreatment and time $(\mathrm{F}(2,105)=5.60 ; p<0.01)$. At $3 \mathrm{~h}$ after the priming injection, animals of both the AMPNPAIR group (in which the priming $5.0 \mathrm{mg} / \mathrm{kg}$ AMP

Table I Total Score of Stereotyped Behavior during I 50 min after Saline or $5.0 \mathrm{mg} / \mathrm{kg}$ Amphetamine i.p. Acute Administration

\begin{tabular}{lc}
\hline Injection & Total stereotypy score \\
\hline Saline & $15.80 \pm 2.66$ \\
Amphetamine & $38.80 \pm 1.28 \%$ \\
\hline
\end{tabular}

* $p<0.05$ compared to saline-treated mice. Student's $t$-test. injection was not paired to the stereotypy observation cages) and AMP-PAIR group (in which the $5.0 \mathrm{mg} / \mathrm{kg}$ AMP priming injection was paired to the stereotypy observation cages) showed significantly higher SB than that presented by animals of their respective control (SALpretreated) groups $(\mathrm{F}(11,105)=12.89 ; p<0.001)$. At 4 and $5 \mathrm{~h}$ after the priming injection, only animals of the AMPPAIR group presented a significantly higher stereotypy than that presented by their respective control (SAL) groups as well as significantly higher than that presented by animals of the respective AMP-NPAIR group, including the $3-\mathrm{h}$ interval.

\section{Experiment 3. Rapid-Onset Sensitization of AMP-Induced SB in Mice: Effect of a Higher Dose of AMP Challenge Injection}

Figure 3 shows SB induced by $5.0 \mathrm{mg} / \mathrm{kg}$ AMP in animals pretreated with a priming injection of SAL or $5.0 \mathrm{mg} / \mathrm{kg}$ AMP given 3, 4, or $5 \mathrm{~h}$ before. A three-way ANOVA revealed significant effects for pretreatment (SAL or AMP) $(\mathrm{F}(1,108)=124.67 ; p<0.001)$, pairment (NPAIR or PAIR) $(\mathrm{F}(1,108)=10.49 ; p<0.001)$, and time $(3,4$, or $5 \mathrm{~h}$ after injection) $(\mathrm{F}(2,108)=6.28 ; p<0.001)$, as well as for interaction between pretreatment and pairment $(\mathrm{F}(1,108)=6.39$; $p<0.001)$. At 3,4 , or $5 \mathrm{~h}$ after the priming injection, animals of the AMP-NPAIR and AMP-PAIR groups presented significantly higher $\mathrm{SB}$ than that presented by their respective control (SAL) groups $(\mathrm{F}(11,108)=14.21$; $p<0.001)$. At 4 and $5 \mathrm{~h}$ after the priming injection, animals of the AMP-PAIR group also presented a significant increase in SB when compared to animals of the AMPNPAIR group.

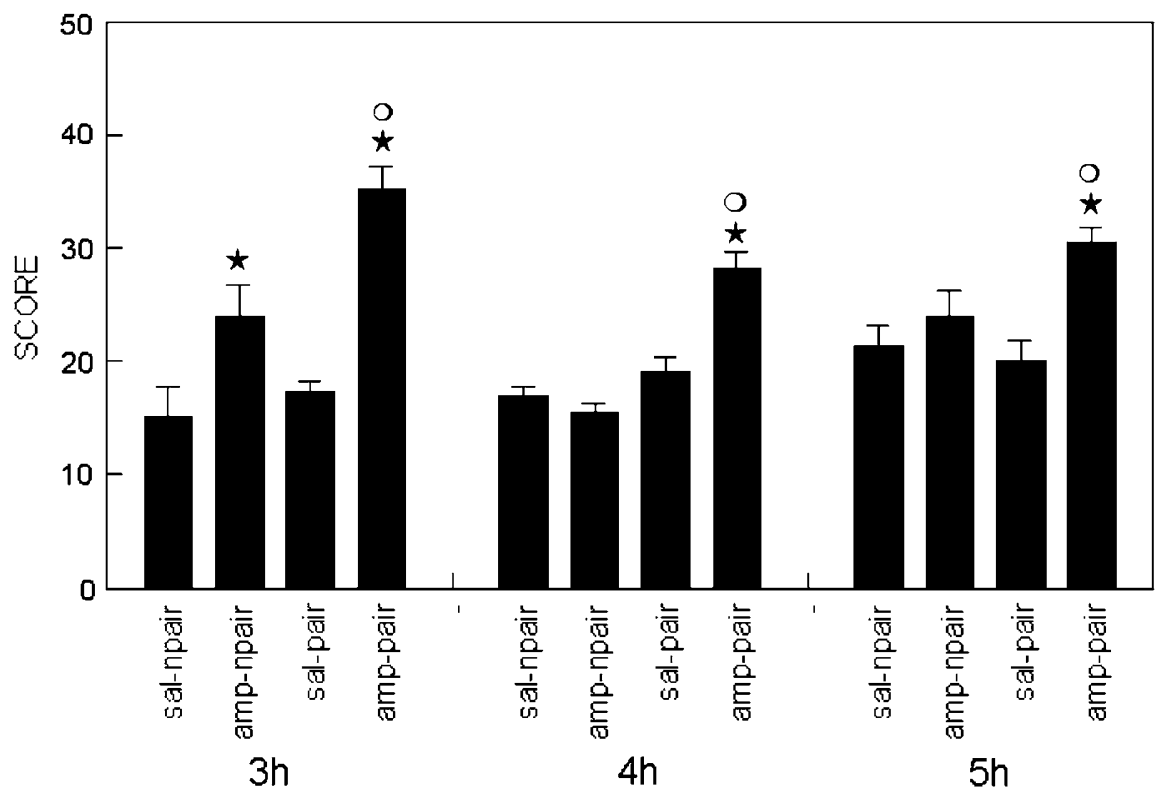

Figure 2 Experiment 2. Validation of the phenomenon of rapid-onset sensitization of AMP-induced SB in mice and possible involvement of drugenvironment association. Animals $(n=8-10)$ received a SAL or $5.0 \mathrm{mg} / \mathrm{kg}$ AMP priming injection and were paired (PAIR) or not (NPAIR) to the stereotypy observation cages as described in experimental procedure. At 3, 4, or $5 \mathrm{~h}$ after their respective priming injections, all the animals received $1.5 \mathrm{mg} / \mathrm{kg}$ AMP and, immediately later, were placed in stereotypy observation cages for SB quantification. ${ }^{*} p<0.00$ I compared to the SAL group with the same conditions of pairment and interval between injections. $O, p<0.00$ I compared to the N-PAIR group with the same conditions of pretreatment and interval between injections. ANOVA followed by Duncan test. 


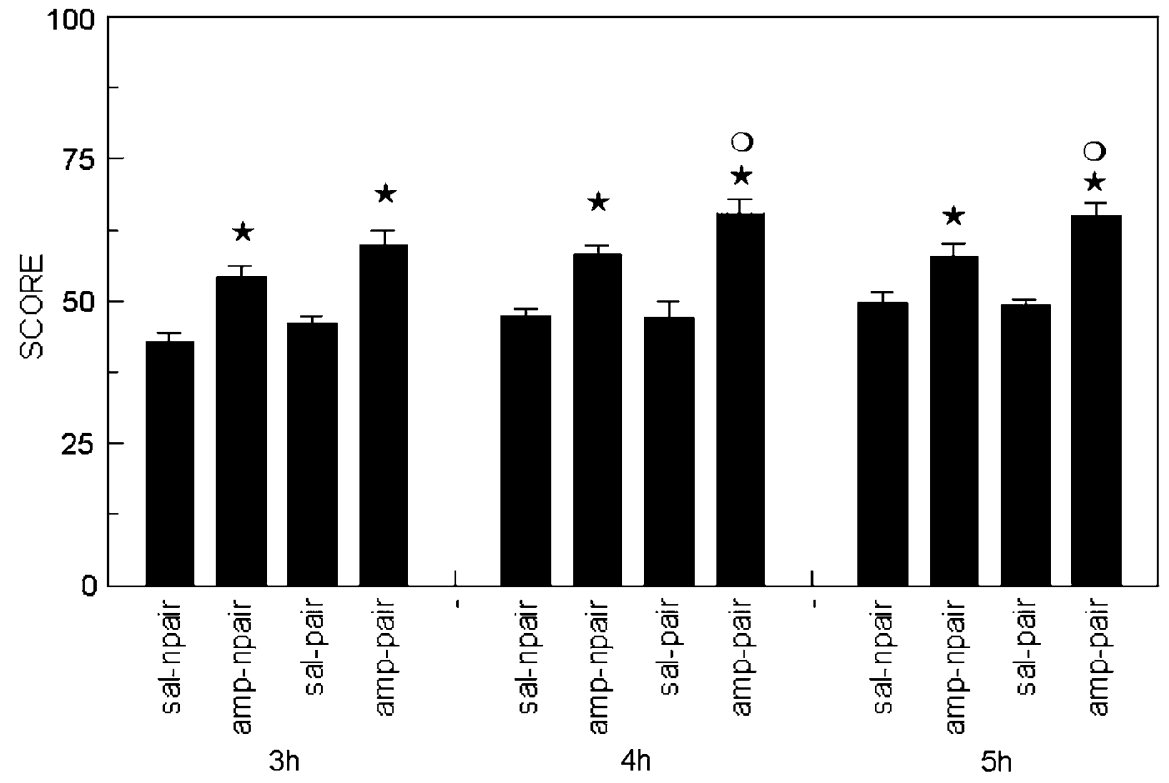

Figure 3 Experiment 3. Rapid-onset sensitization of AMP-induced SB in mice and possible involvement of drug-environment association: effect of a higher dose of AMP challenge injection. Animals $(n=10)$ received a SAL or $5.0 \mathrm{mg} / \mathrm{kg}$ AMP priming injection and were paired (PAIR) or not (NPAIR) to the stereotypy observation cages as described in experimental procedure. At 3, 4, or $5 \mathrm{~h}$ after their respective priming injections, all the animals received 5.0 mg/ $\mathrm{kg}$ AMP and, immediately later, were placed in stereotypy observation cages for SB quantification. ${ }^{*} p<0.00$ I compared to the SAL group with the same conditions of pairment and interval between injections. $O, p<0.001$ compared to the N-PAIR group with the same conditions of pretreatment and interval between injections. ANOVA test followed by Duncan test.

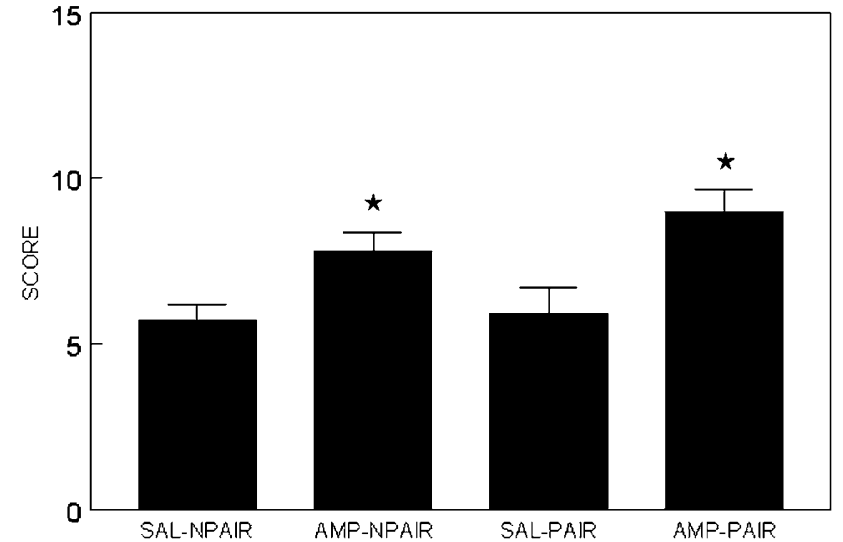

Figure 4 Experiment 4A. Rapid-onset sensitization of AMP-induced SB in mice and possible involvement of drug-environment association: effect of a SAL challenge injection. Animals $(n=9-10)$ received a SAL or $5.0 \mathrm{mg} /$ $\mathrm{kg}$ AMP priming injection which was paired (PAIR) or not (NPAIR) to the stereotypy observation cages. At $3 \mathrm{~h}$ after their respective priming injections, all the animals received a SAL challenge injection and, immediately later, were placed in the stereotypy observation cages for $S B$ quantification. ${ }^{*} p<0.05$ compared to the respective SAL group. ANOVA followed by Duncan test.

\section{Experiment 4. Rapid-Onset Sensitization of AMP-Induced SB in Mice and Possible Involvement of Drug-Environment Association: Effect of a SAL Challenge Injection}

Figures 4 and 5 show the effects of a SAL challenge injection 3 or $4 \mathrm{~h}$ after the priming injection of SAL or $5.0 \mathrm{mg} / \mathrm{kg}$ AMP, respectively. Concerning the 3-h interval, a two-way ANOVA revealed a significant effect of pretreatment only

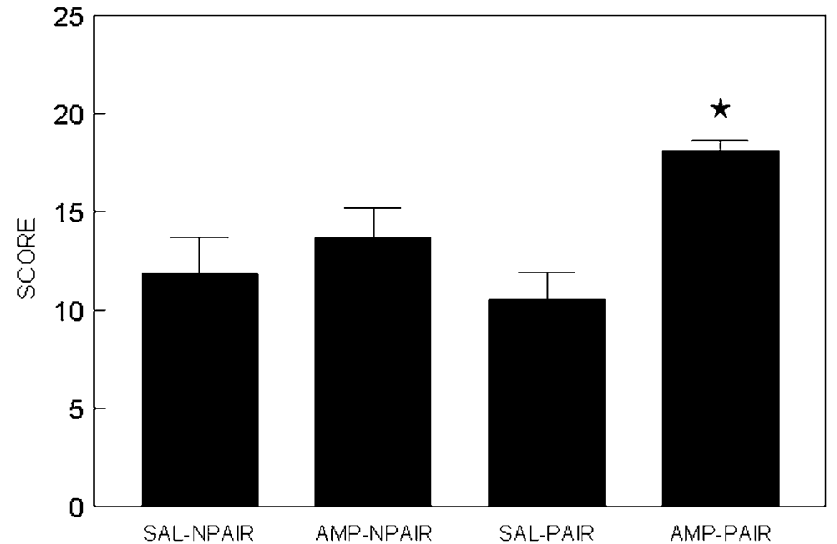

Figure 5 Experiment 4B. Rapid-onset sensitization of AMP-induced SB in mice and possible involvement of drug-environment association: effect of a SAL challenge injection. Animals $(n=9-10)$ received a SAL or $5.0 \mathrm{mg} /$ $\mathrm{kg}$ AMP priming injection which was paired (PAIR) or not (NPAIR) to the stereotypy observation cages. At $4 \mathrm{~h}$ after their respective priming injections, all the animals received a SAL challenge injection and, immediately later, were placed in the stereotypy observation cages for SB quantification. ${ }^{*} p<0.05$ compared to the respective SAL group. ANOVA followed by Duncan test.

$($ SAL or AMP) $(\mathrm{F}(1,35)=16.01 ; p<0.001)$. Indeed, animals of both groups that had received a previous injection of AMP (AMP-NPAIR and AMP-PAIR groups) presented a significantly higher SB than that presented by the respective animals of control (SAL) groups. At $4 \mathrm{~h}$ after the priming injections, a two-way ANOVA revealed a significant effect of pretreatment (SAL or AMP) $(\mathrm{F}(1,36)=11.23 ; p<0.05)$. The interaction between pretreatment and pairment conditions just missed significance $(\mathrm{F}(1,36)=4.04 ; p=0.052)$. Indeed, 
only the animals of the AMP-PAIR group (and not those of the AMP-NPAIR group) presented a significant increase in stereotypy when compared to the respective control (SAL) pretreated group.

\section{Experiment 5. Demonstration of the LSE of $5.0 \mathrm{mg} / \mathrm{kg}$ in the Open-Field Behavior of Mice}

Student's $t$-test showed that mice acutely treated with an intraperitoneal injection of $5.0 \mathrm{mg} / \mathrm{kg}$ AMP presented a significantly higher locomotion frequency $(556.5 \pm 23.5-$ mean \pm SE) than that presented by animals acutely treated with SAL $(116.2 \pm 9.3)(T(12)=15.40 ; p<0.001)$.

Experiment 6. Demonstration of the Phenomenon of Rapid-Onset Sensitization of AMP-Induced Locomotor Activation in Mice and the Involvement of Drug-Environment Association

A two-way ANOVA revealed significant effects of pretreatment (SAL or AMP) $(\mathrm{F}(1,36)=78.00 ; p<0.001)$, pairment (NPAIR and PAIR) $(\mathrm{F}(1,36)=26.15 ; p<0.001)$, and interaction between both factors $(\mathrm{F}(1,36)=30.16 ; p<0.001)$. Figure 6 shows that animals of the AMP-PAIR group presented a significantly higher locomotion frequency than that presented by all the other groups $(\mathrm{F}(3,36)=44.77$; $p<0.001)$. In addition, animals of the AMP-NPAIR group presented locomotion frequency higher than that presented by animals of the respective control group SAL-NPAIR (Figure 6).

\section{Experiment 7. Rapid-Onset Sensitization of} AMP-Induced Locomotor Stimulation in Mice and Possible Involvement of Drug-Environment Association: Effect of a SAL Challenge Injection

In experiment 7 , two-way ANOVA revealed significant effects of pretreatment (SAL or AMP) $(\mathrm{F}(1,35)=24.26$;

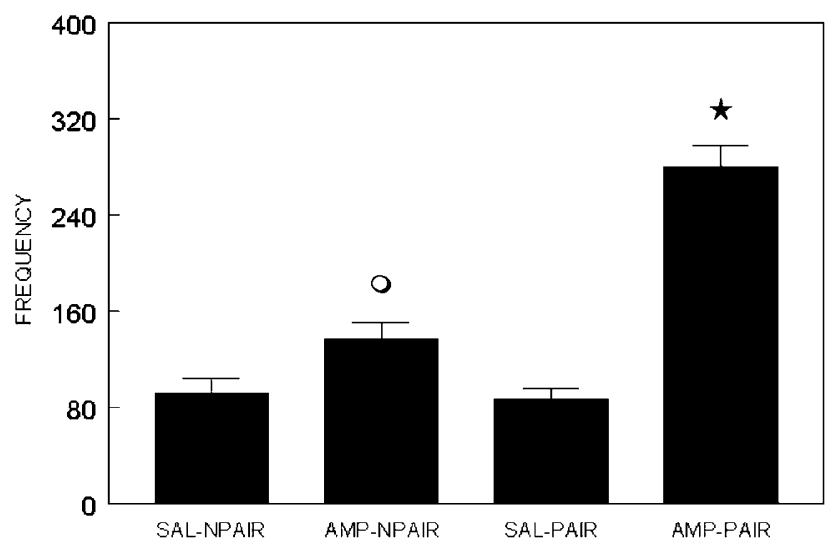

Figure 6 Experiment 6. Demonstration of the phenomenon of rapidonset sensitization of AMP-induced locomotor activation in mice and the involvement of drug-environment association. Animals $(n=10)$ received a SAL or $5.0 \mathrm{mg} / \mathrm{kg}$ AMP priming injection which was paired (PAIR) or not (NPAIR) to the open-field apparatus. At $4 \mathrm{~h}$ after their respective priming injections, all the animals received $1.5 \mathrm{mg} / \mathrm{kg}$ AMP challenge injection and I 5 min later their open-field locomotor activity was quantified. ${ }^{*} p<0.00$ I compared to the other groups. $\bigcirc, p<0.00 \mathrm{I}$ compared to the respective SAL group (SAL-NPAIR). ANOVA followed by Duncan test.

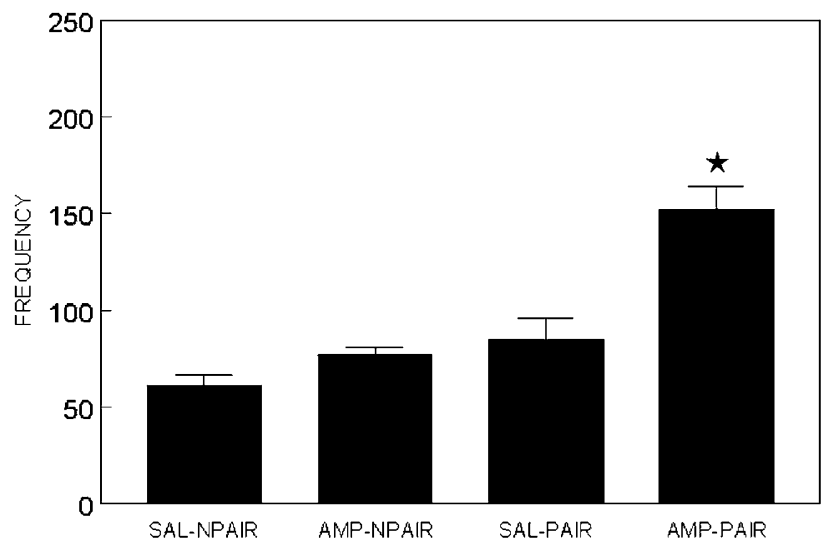

Figure 7 Experiment 7. Rapid-onset sensitization of AMP-induced locomotor stimulation in mice and possible involvement of drugenvironment association: effect of a SAL challenge injection. Animals $(n=9-10)$ received a SAL or $5.0 \mathrm{mg} / \mathrm{kg}$ AMP priming injection which was paired (PAIR) or not (NPAIR) to the open-field apparatus. At $4 \mathrm{~h}$ after their respective priming injections, all the animals received a SAL challenge injection and 15 min later their open-field locomotor activity was quantified. ${ }^{*} p<0.00$ I compared to all other groups. ANOVA followed by Duncan test.

$p<0.001)$, pairment (NPAIR or PAIR) $(\mathrm{F}(1,35)=34.93$; $p<0.001)$, and interaction between both factors $(\mathrm{F}(1,35)=$ 9.23; $p<0.001)$. Figure 7 shows that animals of the AMPPAIR group presented a significant increase in locomotion frequency when compared to all the other groups $(\mathrm{F}(3,35)=21.75 ; p<0.001)$.

\section{DISCUSSION}

The major findings of the present study were that: (1) as previously demonstrated in the rat (Kuczenski and Segal, 1999a, b), a priming injection of a high dose of AMP induced a very rapid $(3-5 \mathrm{~h})$-onset sensitization to the $\mathrm{SB}$ induced by a subsequent injection of both a low or a high dose of the drug, in the mouse; (2) opposite to previously described in the rat (Kuczenski and Segal, 1999a), a rapidonset sensitization to the locomotor-stimulating effect of AMP was also demonstrated in the mouse, and (3) this rapid-onset behavioral sensitization to AMP in mice did not require environmental conditioning to develop, but a conditioned association between the drug effect and the environment in which the behavior was quantified markedly increased the magnitude of the sensitization phenomenon.

The first series of experiments presented in our study - related to AMP-induced SB in the mouse-markedly replicates the stereotypy data of Kuczenski and Segal (1999a), in rats. Indeed, in the latter study, it was demonstrated that after a priming AMP dose of $4.0 \mathrm{mg} / \mathrm{kg}$ and a low-dose challenge of $0.5 \mathrm{mg} / \mathrm{kg}$, significant sensitization to SB was verified only when the challenge injection was administered $3 \mathrm{~h}$ (but not 4 or $5 \mathrm{~h}$ ) after the priming injection. However, when rats were challenged with a higher dose $(1.5 \mathrm{mg} / \mathrm{kg})$ of AMP, sensitization to SB was significant at all tested intervals $(3,4$, and $5 \mathrm{~h})$. In the present study, after a priming AMP dose of $5.0 \mathrm{mg} / \mathrm{kg}$ and a low-dose (for 
mice) challenge of $1.5 \mathrm{mg} / \mathrm{kg}$, significant sensitization to stereotypy was also verified at $3 \mathrm{~h}$ (but not 4 or $5 \mathrm{~h}$ ) intervals. Notwithstanding, sensitization was significant at all intervals tested when the challenge dose of AMP was increased $(5.0 \mathrm{mg} / \mathrm{kg})$. Taken together, the present data and those reported by Kuczenski and Segal (1999a) suggest that this rapid-onset sensitization to AMP-induced SB is a quite consistent and reproducible phenomenon, even in a different species.

Although confirming the notion that this rapid-onset sensitization to AMP-induced SB can develop in the absence of environmental conditioning (Kuczenski and Segal, 1999a), our data clearly show that such a conditioning can strongly potentiate this kind of sensitization. Indeed, when the behavioral effect (stereotypy) induced by AMP priming injection had been paired to the observation cage, the intensity of SB induced by a challenge (both 1.5 and 5.0 $\mathrm{mg} / \mathrm{kg}$ ) injection of the drug was always (at all intervals) significantly enhanced as compared to control animals equally paired to environment but 'primed' with SAL. In addition, with the exception of the 3 -h interval in experiment 2 (challenge with $5.0 \mathrm{mg} / \mathrm{kg}$ ), the SB of these mice was also always significantly higher than that presented by animals that had been equally 'primed' with AMP but had not been paired to the observation cage. Furthermore, when animals that had received a priming injection of AMP paired to the observation cage were challenged with SAL $4 \mathrm{~h}$ later, they presented a significant increase in spontaneous SB as compared to all the other groups.

Interestingly, at the $3 \mathrm{~h}$ interval, mice that received a priming injection of AMP presented a significant increase in spontaneous stereotypy (SAL challenge) irrespective of the pairment condition. At first, one could argue that this effect could be due to residual levels of AMP or increased extracellular dopamine. However, this appears not to be the case since we demonstrated that $140 \mathrm{~min}$ after the priming injection of AMP $(5.0 \mathrm{mg} / \mathrm{kg}) \mathrm{SB}$ had completely ceased (see Figure 1). According to this analysis, Kuczenski and Segal (1999a) demonstrated that the rapid-onset (three-hour interval) sensitization to AMP in rats occurred without a corresponding increase in extracellular dopamine levels. In this respect, after AMP administration, extracellular dopamine concentrations are highly correlated with extracellular concentrations of AMP, and the rate constants for the decline of extracellular dopamine, extracellular AMP, and tissue levels of AMP are comparable (Kuczenski et al, 1997). Thus, an alternative hypothesis to explain the spontaneous stereotypy presented $3 \mathrm{~h}$ later by mice which had received a priming dose of AMP in the absence of environmental pairment might be the development of a Pavlovian conditioning between AMP-induced SB and the injection procedure. In this respect, priming intraperitoneal injection of AMP was accompanied by a number of cues predictive of drug administration, such as the appearance of the experimenter, handling, and a needle prick. This injection procedure conditioning to drug behavioral effects has been clearly demonstrated previously (Chinen and Frussa-Filho, 1999). In line with the above-discussed possibility, while it is well known that conditioned responses declined with time, the spontaneous stereotypy presented by mice previously treated with a nonenvironmental paired priming injection of AMP was no longer present when the interval between the priming injection of AMP and the challenge injection of SAL was increased to $4 \mathrm{~h}$.

The demonstration that drug-environmental conditioning, although not necessary for, can powerfully potentiate the development of the rapid-onset sensitization to AMPinduced SB is completely in line with the current notion of the influence of such a conditioning mechanism on the classic (late onset and associated with repeated AMP administration) behavioral sensitization phenomenon (see Robinson and Becker (1986) and Introduction). Thus, both the rapid- and the late-onset types of the behavioral sensitization phenomenon appear to share some common mechanisms and characteristics. In terms of this conceptualization, Kuribara $(1994,1996)$ demonstrated that although the ambulation-increasing effect of methAMP disappeared by $3 \mathrm{~h}$ after the administration of the drug, a 3 -h post-treatment with different neuroleptic agents after each metAMP administration was effective for a significant inhibition of the induction of the sensitization induced by repeated treatment with the psychostimulant. Thus, stimulation of dopamine receptors during the early posttreatment period following each drug administration may be critical for the development of the behavioral sensitization phenomenon.

One of the most important findings of the present investigation was that the rapid-onset kind of the behavioral sensitization phenomenon was not specific for AMPinduced stereotypies, but was also demonstrated for AMPinduced LSE in mice. This result differs from that of Kuczenski and Segal (1999a) who found that the LSE of AMP did not undergo to rapid-onset sensitization in rats. Perhaps, more important than differences in experimental subjects (rats $\times$ mice), differences in the methodological quantification of stereotyped and locomotor behaviors may account for these differences in results. Indeed, in the study of Kuczenski and Segal (1999a, b), both kinds of behavior were quantified in the same experimental rectangular chambers. Possibly because of the lack of specificity of the chamber to measure each behavior, there was a clear-cut competition between locomotor and SB such that stereotypy replaced locomotor activation. In the present study, the use of a circular open-field apparatus (without corners) to specifically measure locomotor behavior as well as the use of rectangular wire mesh cages to measure SB allowed the expression of the locomotor activating and the stereotyped effects of AMP, at the same doses.

Most, if not all, drugs with abuse potential stimulate locomotion in rodents. This locomotor stimulation has been extensively related to increased dopaminergic neurotransmission in the mesoaccumbens system (Kelly et al, 1975; Pijnenburg et al, 1975; Delfs et al, 1990), which has been extensively related to drug reward (Di Chiara and Imperato, 1988; Koob, 1992; Weiss et al, 1992; Self and Nestler, 1995). Within this context, sensitization to the LSE of AMP and other drugs of abuse has been hypothesized to reflect neuronal adaptations which seem to be crucial to the development of drug addiction (Wise and Bozarth, 1987; Robinson and Berridge, 1993). The present study shows that - in contrast to the initial conclusions of Kuczenski and Segal (1999a,b) - there is a clear-cut rapid-onset sensitization to the AMP-induced locomotor-activating 
effect, which is powerfully potentiated by environmental conditioning. The basic as well as the clinical implications of such a finding may be far reaching.

A final comment concerns the demonstration of environmental cue-induced conditioned stereotyped and locomotor responses after a single environment-drug effect pairment (SAL challenge experiments). Independently of the ability to potentiate the behavioral sensitization phenomenon, these conditioned responses are per se considered animal models to study addiction (Damianopoulos and Carey, 1992; Carey and Damianopoulos, 1994; Hotsenpiller et al, 2002; Hotsenpiller and Wolf, 2002a). Within this context, it has been shown that conditioned locomotion is not directly correlated to behavioral sensitization to psychostimulants (Carey and Gui, 1998; Hotsenpiller et al, 2001; Hotsenpiller and Wolf, 2002b). Thus, the demonstration of a very quick and simple experimental design to specifically study such an important conditioning phenomenon may be of considerable methodological interest.

\section{ACKNOWLEDGEMENTS}

We thank Ms Teotila RR Amaral and Mr Cleomar S Ferreira for capable technical assistance. The research was supported by a fellowship from the Fundação de Amparo a Pesquisa do Estado de São Paulo (FAPESP), from the Conselho Nacional de Desenvolvimento Científico e Tecnológico (CNPq), from the Fundação Coordenação de Aperfeiçoamento de Pessoal de Nível Superior (CAPES), from the Fundo de Auxílio aos Docentes e Alunos da UNIFESP (FADA), and from the Associação Fundo de Incentivo à Psicofarmacologia (AFIP).

\section{REFERENCES}

Bellot RG, Camarini R, Vital MA, Palermo-Neto J, Leyton V, Frussa-Filho R (1996). Monosialoganglioside attenuates the excitatory and behavioural sensitization effects of ethanol. Eur J Pharmacol 313: 175-179.

Bellot RG, Vital MA, Palermo-Neto J, Frussa-Filho R (1997). Repeated monosialoganglioside administration attenuates behavioral sensitization to amphetamine. Brain Res 747: 169-172.

Browne RG, Segal DS (1977). Metabolic and experimental factors in the behavioral response to repeated amphetamine. Pharmacol Biochem Behav 6: 545-552.

Camarini R, Frussa-Filho R, Monteiro MG, Calil HM (2000). MK801 blocks the development of behavioral sensitization to the ethanol. Alcohol Clin Exp Res 24: 285-290.

Carey RJ, Damianopoulos EN (1994). Conditioned cocaine induced hyperactivity: an association with increased medial prefrontal cortex serotonin. Behav Brain Res 62: 177-185.

Carey RJ, Gui J (1998). Cocaine conditioning and cocaine sensitization: what is the relationship? Behav Brain Res 92: 67-76.

Carter BL, Tiffany ST (1999). Meta-analysis of cue-reactivity in addiction research. Addiction 94: 327-340.

Childress AR, McLellan T, O'Brien CP (1986). Abstinent opiate abusers exhibit conditioned craving, conditioned withdrawal and reductions in both through extinction. $\mathrm{Br} J$ Addict 81: 655-660.

Chinen CC, Frussa-Filho R (1999). Conditioning to injection procedures and repeated testing increase SCH 23390-induced catalepsy in mice. Neuropsychopharmacology 21: 670-678.
Costa FG, Frussa-Filho R, Felicio LF (2001). The neurotensin receptor antagonist, SR48692, attenuates the expression of amphetamine-induced behavioural sensitisation in mice. Eur $J$ Pharmacol 428: 97-103.

Damianopoulos EN, Carey RJ (1992). Conditioning, habituation and behavioral reorganization factors in chronic cocaine effects. Behav Brain Res 49: 149-157.

De Vries TJ, Schoffelmeer AN, Binnekade R, Mulder AH, Vanderschuren LJ (1998). Drug-induced reinstatement of heroin- and cocaine-seeking behaviour following long-term extinction is associated with expression of behavioural sensitization. Eur J Neurosci 10: 3565-3571.

Delfs JM, Schreiber L, Kelley AE (1990). Microinjection of cocaine into the nucleus accumbens elicits locomotor activation in the rat. J Neurosci 10: 303-310.

Di Chiara G, Imperato A (1988). Drugs abused by humans preferentially increase synaptic dopamine concentrations in the mesolimbic system of freely moving rats. Proc Natl Acad Sci USA 85: 5274-5278.

Ellison GD, Morris W (1981). Opposed stages of continuous amphetamine administration: parallel alterations on motor stereotypes and in vivo spiroperidol accumulation. Eur $J$ Pharmacol 74: 207-214.

Frussa-Filho R, Goncalves MT, Andersen ML, de Araujo NP, Chinen CC, Tufik S (2004). Paradoxical sleep deprivation potentiates amphetamine-induced behavioural sensitization by increasing its conditioned component. Brain Res 1003: 188-193.

Hayashi T, Ohashi K, Tadokoro S (1980). Conditioned drug effects to $\mathrm{d}$-amphetamine- and morphine-induced motor acceleration in mice: experimental approach for placebo effect. Jpn J Pharmacol 30: 93-100.

Henry DJ, White FJ (1991). Repeated cocaine administration causes persistent enhancement of D1 dopamine receptor sensitivity within the rat nucleus accumbens. J Pharmacol Exp Ther 258: 882-890.

Hotsenpiller G, Giorgetti M, Wolf ME (2001). Alterations in behaviour and glutamate transmission following presentation of stimuli previously associated with cocaine exposure. Eur J Neurosci 14: 1843-1855.

Hotsenpiller G, Horak BT, Wolf ME (2002). Dissociation of conditioned locomotion and Fos induction in response to stimuli formerly paired with cocaine. Behav Neurosci 116: 634-645.

Hotsenpiller G, Wolf ME (2002a). Conditioned locomotion is not correlated with behavioral sensitization to cocaine: an intralaboratory multi-sample analysis. Neuropsychopharmacology 27: 924-929.

Hotsenpiller G, Wolf ME (2002b). Extracellular glutamate levels in prefrontal cortex during the expression of associative responses to cocaine related stimuli. Neuropharmacology 43: 1218-1229.

Kelly PH, Seviour PW, Iversen SD (1975). Amphetamine and apomorphine responses in the rat following 6-OHDA lesions of the nucleus accumbens septi and corpus striatum. Brain Res 94: 507-522.

Kolta MG, Shreve P, De Souza V, Uretsky NJ (1985). Time course of the development of the enhanced behavioral and biochemical responses to amphetamine after pretreatment with amphetamine. Neuropharmacology 24: 823-829.

Koob GF (1992). Neural mechanisms of drug reinforcement. Ann N Y Acad Sci 54: 171-191.

Kuczenski R, Melega WP, Cho AK, Segal DS (1997). Extracellular dopamine and amphetamine after systemic amphetamine administration: comparison to the behavioral response. $J$ Pharmacol Exp Ther 282: 591-596.

Kuczenski R, Segal DS (1999a). Sensitization of amphetamineinduced stereotyped behaviors during the acute response. $J$ Pharmacol Exp Ther 288: 699-709. 
Kuczenski R, Segal DS (1999b). Sensitization of amphetamineinduced stereotyped behaviors during the acute response: role of D1 and D2 dopamine receptors. Brain Res 822: 164-174.

Kuribara H (1994). Early post-treatment with haloperidol retards induction of metamphetamine sensitization in mice. Eur J Pharmacol 256: 295-299.

Kuribara H (1996). Effects of sulpiride and nemonapride, benzamide derivatives having distinct potencies of antagonistic action on dopamine D2 receptors, on sensitization to metamphetamine in mice. J Pharm Pharmacol 48: 292-296.

Niaura RS, Rohsenow DJ, Binkoff JA, Monti PM, Pedraza M, Abrams DB (1988). Relevance of cue reactivity to understanding alcohol and smoking relapse. J Abnorm Psychol 97: 133-152.

Paulson PE, Camp DM, Robinson TE (1991). Time course of transient behavioral depression and persistent behavioral sensitization in relation to regional brain monoamine concentrations during amphetamine withdrawal in rats. Psychopharmacology (Berlin) 103: 480-492.

Piazza PV, Deminiere JM, le Moal M, Simon H (1990). Stress- and pharmacologically-induced behavioral sensitization increases vulnerability to acquisition of amphetamine self-administration. Brain Res 514: 22-26.

Pierce RC, Kalivas PW (1997). A circuitry model of the expression of behavioral sensitization to amphetamine-like psychostimulants. Brain Res Rev 25: 192-216.

Pijnenburg AJ, Honig WM, Van Rossum JM (1975). Inhibition of D-amphetamine-induced locomotor activity by injection of haloperidol into the nucleus accumbens of the rat. Psychopharmacologia 41: 87-95.

Robinson TE, Becker JB (1986). Enduring changes in brain and behavior produced by chronic amphetamine administration: a review and evaluation of animal models of amphetamine psychosis. Brain Res Rev 11: 157-198.

Robinson TE, Berridge KC (1993). The neural basis of drug craving: an incentive-sensitization theory of addiction. Brain Res Rev 18: 247-291.

Self DW, Nestler EJ (1995). Molecular mechanisms of drug reinforcement and addiction. Ann Rev Neurosci 18: 463-495.

Setler P, Sarau H, Mckenzie G (1976). Differential attenuation of some effects of haloperidol in rats given scopolamine. Eur $J$ Pharmacol 39: 117-126.

Vanderschuren LJ, Schmidt ED, De Vries TJ, Van Moorsel CA, Tilders FJ, Schoffelmeer AN (1999a). A single exposure to amphetamine is sufficient to induce long-term behavioral, neuroendocrine, and neurochemical sensitization in rats. J Neurosci 19: 9579-9586.

Vanderschuren LJ, Schoffelmeer AN, Mulder AH, De Vries TJ (1999b). Dopaminergic mechanisms mediating the long-term expression of locomotor sensitization following pre-exposure to morphine or amphetamine. Psychopharmacology (Berlin) 143: 244-253.

Weiss F, Hurd YL, Ungerstedt U, Markou A, Plotsky PM, Koob GF (1992). Neurochemical correlates of cocaine and ethanol selfadministration. Ann N Y Acad Sci 654: 220-241.

Wise RA, Bozarth MA (1987). A psychomotor stimulant theory of addiction. Psychological Rev 94: 469-492.

Wise RA, Gingras MA, Amit Z (1996). Influence of novel and habituated testing conditions on cocaine sensitization. Eur J Pharmacol 307: 15-19.

Wolf ME, White FJ, Hu XT (1994). MK-801 prevents alterations in the mesoaccumbens dopamine system associated with behavioral sensitization to amphetamine. J Neurosci 14(Part 2): 1735-1745. 